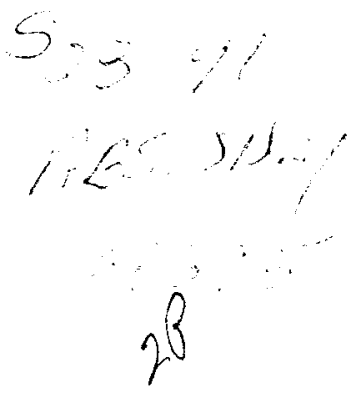

\title{
N89-26362
}

\section{ARE THERE CARBONATE DEPOSITS IN THE VALLES MARINERIS, MARS?}

\author{
Susan S. Nedell and Christopher P. McKay \\ Solar System Exploration Branch \\ NASA Ames Research Center $n(47365$ ) \\ Moffett Field, CA 94035
}

The interiors of the Valles Marineris canyon system contain plateaus of horizontally-layered material where individual layers are laterally continuous over tens of kilometers. Several workers have suggested that they were deposited in lakes that existed in these depressions early in Martian history. Recently, Nedell et al. (1987) conducted a detailed study of the Valles Marineris layered deposits using late Viking high-resolution images. These studies show that the deposits form thick sequences of rhythmically layered material whose bases are in the lowest elevations of the canyon floors and whose tops are commonly within a few hundred meters of the surrounding plateaus. Most of the deposits occupy the central canyons, which include Hebes, Ophir, Candor, and Melas chasmata. From stratigraphic relationships, Nedell et al. (1987) concluded that the layered deposits formed during roughly the same epoch in which the original tectonic canyons were enlarged by ground ice removal and collapse. Later, the deposits were eroded in some locations, producing their present geometry. This erosional episode may coincide with the formation of the large outflow channels that emanate from the east end of the Valles Marineris. Nedell et al. (1987) concluded that deposition in standing water was the only mechanism that could readily explain the distribution, lateral continuity, horizontality, great thickness, and rhythmic nature of the deposits.

If standing bodies of water formed in the Valles Marineris, and an initial thick $\mathrm{CO}_{2}$ atmosphere had thinned resulting in lower temperatures, these lakes would almost certainly have been icecovered. We suggest that a considerable fraction of the possible Martian paleolake sediment could be carbonate material that was precipitated in standing water under conditions of high atmospheric pressure of $\mathrm{CO}_{2}$.

One major problem with carbonate formation on early Mars is maintaining significant bodies of liquid water after the mean temperature fell below $273 \mathrm{~K}$. According to the model of Pollack et al. (1987), this would occur when the atmospheric pressure drops below a value of a few bars. Ice-covered lakes fed by transitory surface melting in the Valles Marineris could have provided a stable body of liquid water that would have also had an enhanced level of atmospheric gases. This hypothesis is supported by our observations in the Antarctic dry valleys where perennially frozen lakes contain dissolved atmospheric gases at 200-300\% above the equilibrium level and the mean annual temperature is $253 \mathrm{~K}$. By analogy with these lakes, we suggest that lakes in the canyon system could have contained liquid water long after the mean temperatures on the surface were below freezing.

Using data from perennially-frozen Antarctic lakes, McKay et al. (1985) developed a general energy balance model for determining the thickness of ice on perennially-frozen lakes. We can apply this model to Martian paleolakes by assuming that ablation, dust loading and optical ice properties are the same as in the nominal Antarctic lake model of McKay et al. (1985), and by using the annually averaged sunlight on the equator of Mars, including the lower solar luminosity of the early sun (see e.g., Pollack et al., 1987) and attenuation atmospheric dust arbitrarily chosen to have an optical 
depth of 0.5 . The resulting value of the solar flux is $126 \mathrm{~W} \mathrm{~m}^{-2}$. This yields an ice thickness of $3.4 \mathrm{~m}$ when the mean temperature is $250 \mathrm{~K}$, and $11 \mathrm{~m}$ and $19 \mathrm{~m}$ for mean temperatures of 240 $\mathrm{K}$ and $230 \mathrm{~K}$, respectively. These values for the ice cover compare to the Antarctic lake ice cover thicknesses of 4-6 m. For the same surface temperature, Mars lakes would have thinner ice covers than Antarctic lakes due to the fact that the mean insulation on the primordial equatorial Mars was greater than in Antarctica today $\left(104 \mathrm{~W} \mathrm{~m}^{-2}\right)$. Ice covers on Mars would have been much thicker if ablation rates in a thinning Martian atmosphere were below the Antarctic values (McKay et al., 1985).

Snowmelt and groundwater flow into the lakes would have carried in $\mathrm{CO}_{2}$ and cations leached from the adjacent rocks. The ions and gases would have been concentrated in the lake water due to dissolution upon freezing. Thus the process of inflow of water, freezing, followed by ablation at the ice surface would have concentrated gases and ions in the water column and enhanced carbonate precipitation. This mechanism is known to operate in the Antarctic dry valley lakes where the relatively complete seals of the perennial ice covers result in supersaturated levels of dissolved gases (Wharton et al., 1986, 1987). A similar mechanism is known to result in carbonate precipitation in the Arctic (Hall, 1980).

A search of the recently re-issued Mariner 6/7 Infrared Spectrometer data in the wavelength region between 2 and $6 \mathrm{~mm}$ failed to confirm the presence of carbonates. Due to the fact that no spectral footprints appear to directly overlie the layered deposits, and that deposits may be blanketed by an eolian mantle, this negative result is inconclusive. We feel that the canyon deposits are still a prime site for future searches for carbonates on Mars.

The detection of carbonates at these sites may have important implications for the search for evidence for past life on Mars (McKay, 1986).

\section{REFERENCES}

Hall, D. K. (1980). Mineral precipitation in north slope river icings. Arctic 33, 343-348.

Kahn, R. (1985). The evolution of $\mathrm{CO}_{2}$ on Mars. Icarus 62, 175-190.

McKay, C. P. (1987). Exobiology and future Mars missions: The search for Mars' earliest biosphere. Adv. Space Res. 6, 269-285.

McKay, C. P., G. D. Clow, R. A. Wharton, Jr., and S. W. Squyres (1985). Thickness of ice on perennially frozen lakes. Nature 313, 561-562.

Nedell, S. S., S. W. Squyres, and D. W. Andersen (1987). Origin and evolution of the layered deposits in the Valles Marineris, Mars. Icarus 70, 142-148.

Pollack, J. B., J. F. Kasting, S. M. Richardson, and K. Poliakoff (1987). The case for a wet, warm climate on early Mars. Icarus 71, 203-224.

Wharton, Jr., R. A., C. P. McKay, R. L. Mancinelli, and G. M. Simmons, Jr. (1987). Perennial $\mathrm{N}_{2}$ supersaturation in an Antarctic lake. Nature 325, 343-345.

Wharton, Jr., R. A., C. P. McKay, G. M. Simmons, Jr., and B. C. Parker (1986). Oxygen budget of a perennially ice-covered Antarctic dry valley lake. Limnol. Oceanogr. 31, 437-443. 